\title{
The Maternal and Child Health (MCH) Handbook and its Influence on Health Behaviors: A Literature Review
}

\author{
Shaira Wignarajah ${ }^{1,2 *}$, Shafi U Bhuiyan ${ }^{3}$, Archana Gugathasan ${ }^{4}$
}

\author{
${ }^{1}$ Global Health, McMaster University, Hamilton, CANADA \\ ${ }^{2}$ University of Limerick, School of Medicine, IRELAND \\ ${ }^{3}$ Dalla Lana School of Public Health, Toronto, CANADA \\ ${ }^{4}$ Faculty of Science, McMaster University, Hamilton, CANADA \\ *Corresponding Author: wignarajah.shaira@gmail.com
}

Citation: Wignarajah, S., Bhuiyan, S. U. and Gugathasan, A. (2022). The Maternal and Child Health (MCH) Handbook and its Influence on Health Behaviors: A Literature Review. European Journal of Environment and Public Health, 6(1), em0092. https://doi.org/10.21601/ejeph/11357

ARTICLE INFO

Received: 1 Sep. 2021

Accepted: 28 Sep. 2021

\begin{abstract}
Objectives: The MCH handbook is a health record and home-based information tool that records and provides health information for women throughout their pregnancy, delivery, and postnatal period, and about the child from the years 0-5. A literature review was conducted using current evidence-based results to determine the effectiveness of the MCH handbook

Methods: The Medline Ovid database was searched for "Maternal and Child Health Handbook". Among the 50 results, 17 articles were found to be relevant and thus reviewed.

Results: This literature review revealed that the MCH handbook is an effective tool that positively influences the behaviours of pregnant women in regard to immunizations, breastfeeding, nutrition, child development, and illnesses. Allowing for two-way communication ensures that the health of both pregnant women and their child(ren) are taken care of at an optimal level.

Discussion: There is a need for greater collaboration between governments, the United Nations, donor agencies and NGOs. This will ensure that every mother, regardless of her culture and socioeconomic class, is educated and empowered well enough to positively impact both the health of her own, and her child(ren)'s.
\end{abstract}

Keywords: $\mathrm{MCH}$, maternal health, child health, handbook, health education

\section{INTRODUCTION}

In 2015, the global maternal mortality ratio stood at 216 maternal deaths per 100,000 live births, with maternal mortality being higher in women living in rural areas and among poorer communities (United Nations Economic and Social Council, 2017; World Health Organization, 2016). In 2015, the global neonatal mortality rate was 19 deaths per 1,000 live births, and the mortality rate for children under 5 years of age globally was 43 deaths per 1,000 live births (United Nations Economic and Social Council, 2017). These statistics all point towards the need for a continued focus on maternal, and child health.

The Sustainable Developmental Goals (SDGs) created by the United States sets goals in these areas, through SDG 3 which is focused on 'Good Health and Well-being'. Reaching such goals requires innovation, collaboration, and development, among other necessities. The Maternal and Child Health (MCH) handbook is one tool that helps towards reaching these goals.
The MCH handbook is a health record and home-based information tool that is used by both healthcare workers and the parent(s)/guardian(s) of a child. It records the health information of a woman throughout her pregnancy, delivery, and postnatal period, along with recording the health information of her child from the years $0-5$, thus ensuring a continuum of care. The handbook also consists of health information and guidelines relating to nutrition, immunization, importance of breastfeeding, and ways of taking care of a newborn, among various other topics (Figure 1).

The MCH handbook was first created and distributed in 1942 by the Ministry of Health and Welfare, Japan (Nakamura, 2010). In 1948, Dr. Yakamura and a group of researchers started the International Committee on MCH Handbook (Nakamura, 2010). Through this committee, the handbook is now being used in over 42 countries around the world. The International Committee on MCH Handbook continues to work hard to promote this tool to improve the quality of childcare and ensure that no one is left behind. 


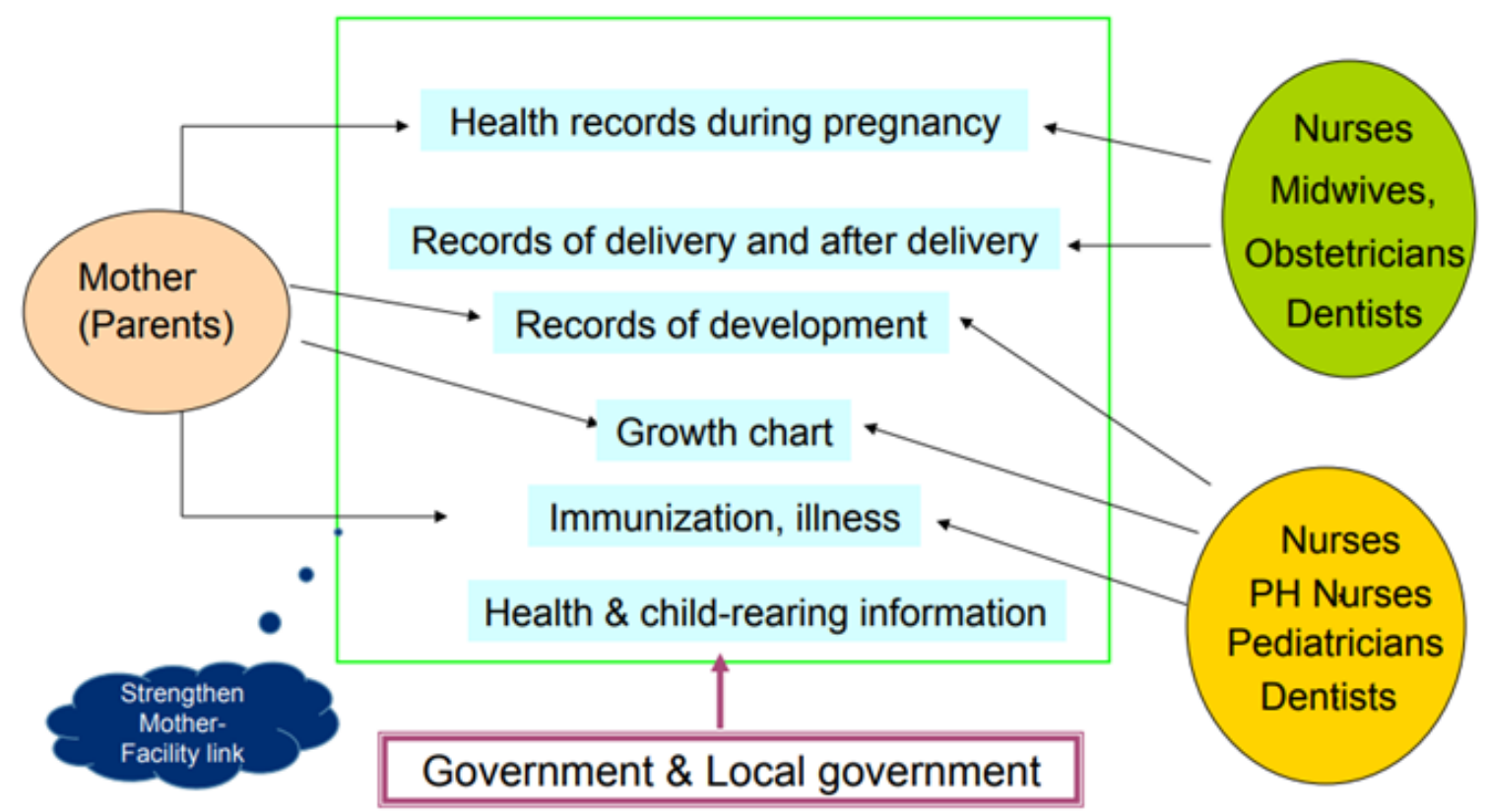

Figure 1. Indicates some of the information included in the $\mathrm{MCH}$ handbooks, along with the individuals who play a role in recording information in it (Nakamura and Bhuiyan, 2005)

Each country has a handbook specific to meeting their country's goals in maternal and child health, and is culturally appropriate, both in terms of the language being used and content, so that the users are able to understand and adequately apply the information that they've learned. A handbook is created and implemented in a country once the Government or a Donor requests it from the International Committee on $\mathrm{MCH}$ Handbook. The Committee plays an advocacy role by offering their expertise and guidance to ensure that an appropriate handbook is created and implemented in the respective heath care system.

This literature review will analyze studies published from 2001 to January 2021 focused on the implementation of a $\mathrm{MCH}$ handbook in various countries to determine its efficacy in positively influencing the health behaviors of women during pregnancy, delivery, and postnatal period, and aid in the health of both the woman and her child. The literature review will include original articles, ensuring that every article that is reviewed is one that is peer reviewed.

\section{METHODS}

Medline Ovid is a database that consists of articles from 1946 - January 2021. This database was searched for "Maternal and Child Health Handbook", which generated 50 results. From this 50, two were found to be literature reviews, and one was a meta-analysis. They were omitted to ensure that there was no duplication of results. At the end, 17 articles were found to be focused on Maternal and Child Health handbook and the impact that they had on maternal behaviours and maternal, newborn, and child health. These 17 articles were reviewed to determine whether the Maternal and Child Health handbook has a positive effect on maternal behaviours and maternal, newborn, and child health (Table 1, Figure 2).

Table 1. Articles reviewed

\begin{tabular}{|c|c|c|}
\hline Art & & Ye \\
\hline Yaternal and Child Health handbook use for maternal a & Osa & 20 \\
\hline $\begin{array}{l}\text { Effectiveness of and factors related to possession of a m } \\
\text { scor }\end{array}$ & $\begin{array}{l}\text { Kawakatsu et } \\
\text { al. }\end{array}$ & 201 \\
\hline The Maternal and Child Health (MCH) handboo & & 2015 \\
\hline Knowledg & & 2015 \\
\hline $\begin{array}{l}\text { Effect of a Maternal and Child Health handbook o } \\
\operatorname{tr}\end{array}$ & et & 201 \\
\hline The role of home-based records in the establishment o & Osal & 201 \\
\hline ernal and Child Health Handbook use for maternal an & Osaki et al. & 201 \\
\hline Is the Maternal and Child Health (MCH) handbook eff & $\begin{array}{r}\text { Hagiw } \\
\mathrm{a}\end{array}$ & 201 \\
\hline The role of home-based records in the establishment o & Osaki et al. & 20 \\
\hline
\end{tabular}


Table 1 (continued). Articles reviewed

\begin{tabular}{|c|c|c|}
\hline Article Title & Authors & Year \\
\hline Maternal and Child Health handbook in Japan & Nakamura & 2010 \\
\hline Maternal and Child Health (MCH) handbook in the world. Maternal and Child Health handbook in Thailand & Isaraunrug & 2009 \\
\hline Development, field testing, and potential benefits of a Maternal and Child Health (MCH) handbook in Bangladesh & Bhuiyan & 2009 \\
\hline Increased utilization of maternal health services by mothers using the Maternal and Child Health handbook in Indonesia & $\begin{array}{c}\text { Kusmayati and } \\
\text { Nakamura }\end{array}$ & 2007 \\
\hline $\begin{array}{l}\text { The evaluation of the official development assistance programme from Jica on The Maternal and Child Health Handbook } \\
\text { at The Telogo Asri Village, Central Java }\end{array}$ & Rukminto & 2006 \\
\hline Study on development and assessment of Maternal and Child Health (MCH) handbook in Bangladesh & Bhuiyan et al. & 2006 \\
\hline $\begin{array}{c}\text { The relationship between retention of the Maternal Child Health handbook, awareness of DPT additional immunization } \\
\text { and DPT additional immunization }\end{array}$ & Jeong & 2004 \\
\hline Utilization of Maternal and Child Health handbook in Japan & Fujimoto et al. & 2001 \\
\hline
\end{tabular}

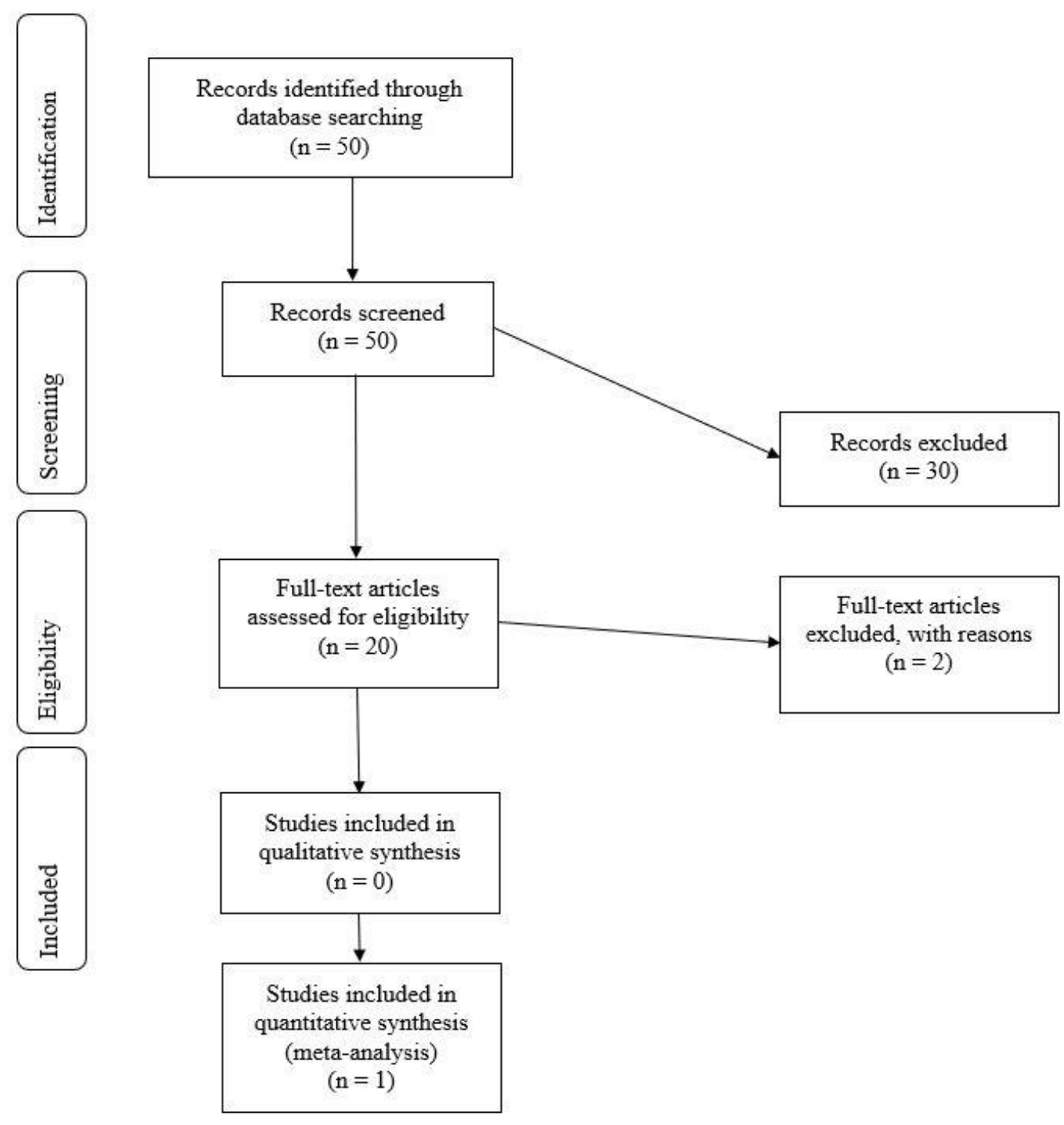

Figure 2. Method used to collect articles

\section{RESULTS}

\section{Using Handbook}

Bhuiyan (2009) found that $83 \%$ of the cohort of pregnant mothers in Bangladesh brought the MCH handbook with them when meeting with healthcare providers. Moreover, this was the only tool that allowed for 2-way communication whereas the usual immunization cards, treatment cards, and antenatal and postnatal cards only allowed for one-way communication, since the patients were not able to write and communicate to their healthcare providers via the cards (Bhuiyan, 2009). 83\% of the cohort were also able to read the handbook, and $76 \%$ were able to write comments in it (Bhuiyan, 2009). These large numbers in Bangladesh suggest that the majority of pregnant women are able to use and communicate via the $\mathrm{MCH}$ Handbook. 
Many of the handbooks consist of illustrations to better understand the health information and guidelines in the book. The illustrations are also useful for women who are illiterate. Using both illustrations and additional explanations from nurses and midwives allows for a better understanding of the information in the $\mathrm{MCH}$ handbooks and make it more accessible to a broader population (Yanagisaw et al., 2015).

Fujimoto et al. (2001) found that among pregnant women in Gifu, Hiroshima, Niligata, Shizoaka, and Yokohama in Japan, 98.3\% of the women who were given a MCH handbook had read it and $97.8 \%$ had written in it. $0.9 \%$ of the women had lost the handbook (Fujimoto et al., 2001). 87\% of the women stated that the MCH handbook was helpful for childbearing, and $81.6 \%$ stated that the handbook was helpful for becoming aware of the required and recommended immunizations (Fujimoto et al., 2001).

A study by Isaranurug found that in 2009 , $83 \%$ of the women in Thailand who used the $\mathrm{MCH}$ handbook had completed the antenatal record in their handbook, 91.1\% had completed the record of Tetanus immunization, and 99\% had completed the record of child vaccines (Isaranurug, 2009). These percentages are larger compared to the data previously recorded in 1995 (Isaranurug, 2009). The study also found that $73.3 \%$ of the mothers read the guidelines for mother's nutrition, $88.5 \%$ read the childcare section, $92.3 \%$ read the child development section, and $90.4 \%$ read the disease prevention section (Isaranurug, 2009). These percentages have increased from the data collected in 1999 (Isaranurug, 2009). The reasoning behind this increase was not studied, but can be attributed to the visual changes that were made to the $\mathrm{MCH}$ handbook in 2002. For example, a more visually stimulating picture was used on the cover, the text on the page were enlarged, and the book was printed in color (Isaranurug, 2009).

Hagiwaraa et al. (2013) found that women in Palestine who were not able to read the handbook themselves, became familiar with the information through guidance by their health providers who recorded information in it. This demonstrates that it is effective and helpful for women regardless of their level of education, considering that their healthcare providers engage with it as well.

\section{Utilization of Medical Services - Health System Strengthening}

Antenatal care (ANC) involves contacting with a health provider upon realization that one is pregnant. Essential interventions in ANC include identification and management of obstetric complications such as preeclampsia, preventive treatments such as those for malaria during pregnancy (IPTp), and identification and management of infections including HIV (Lincetto et al., 2005). It is recommended that throughout one's pregnancy a woman obtains ANC 4-8 times (WHO, 2016). It has been found that a minimum of 8 visits can reduce perinatal deaths by up to 8 per 1000 births, when compared to 4 visits (WHO, 2016). A skilled birth attendant is either a doctor, nurse, or midwife who is present during childbirth. Having access to one during birth has been found to prevent and/or manage obstetric complications (WHO, 2018). ANC promotes the use of a skilled birth attendant, along with breastfeeding, early postnatal care, and planning for optimal pregnancy spacing (Lincetto et al., 2005).
Yanagisawa et al. (2015), in Cambodia, found that upon using the MCH Handbook, there was an increase in the number of pregnant women who went to at least one ANC (90.6\% vs $83.8 \%$, in comparison to the control $81.3 \%$ vs $81.3 \%$ ), and an increase in the number of pregnant women who went four times or more times (45.3\% vs $33.1 \%$, in comparison to the control $39.7 \%$ vs $29.4 \%)$. The number of pregnant women who delivered with a skilled birth attendant also increased (77.2\% vs $53.8 \%$, in comparison to the control $67.8 \%$ vs $56.6 \%$ ) (Yanagisawa et al., 2015). The number of pregnant women who chose to deliver at a health facility as opposed to a home environment also increased ( $74.1 \%$ vs $51.3 \%$, in comparison to the control 52.5\% vs 34.1\%) (Yanagisawa et al., 2015). These numbers indicate that the utilization of the MCH Handbook by pregnant women in Cambodia have increased the utilization of medical services.

Mori et al. (2015) found that pregnant women in Mongolia who used the MCH handbook attended antenatal clinics on average 6.9 times, whereas the control group attended 6.2 times (Mori et al., 2015). Moreover, it was found that pregnancy complications were more likely to be detected among women using the MCH handbook (Mori et al., 2015). The reasons for this were not stated, but it can be related to the fact that using the handbook helps women recognize that they are experiencing one or more of the risk factors, and they then communicate that knowledge to a health worker(s).

Kusumayati and Nakamura (2007) found that pregnant women in Indonesia who owned a MCH handbook were 3 times more likely to use a skilled birth attendant, and 2.5 times more likely to engage in family planning. Furthermore, it was revealed that pregnant women who had read most of, or all sections of the MCH handbook received ANC at least 4 times.

Aiga et al. (2015) found that though a large number of pregnant women in Vietnam knew that at least 3 ANC visits were necessary during pregnancy $(91.9 \%$ in pre-intervention, compared to $93.7 \%$ in post-intervention), the number of women who made more than 3 antenatal visits were significantly higher in the post-intervention than the preintervention (67.5\% in pre-intervention, compared to $92.25 \%$ in post-intervention). Thus deducing, that the $\mathrm{MCH}$ handbook may have played a role in influencing behavioral changes.

Bhuiyan et al. (2009) found that among women in Bangladesh who used the MCH handbook, 78.0\% had an increased knowledge about the importance of antenatal visits, compared to $8.3 \%$ in the control group. The increase in knowledge seemed to have also affected behaviors, since $55.9 \%$ of the women who used the MCH handbook took part in ANC visits, compared to $35.5 \%$ in the control group (Bhuiyan et al., 2009).

\section{Prevention and Elimination - Getting Immunizations}

Immunization controls and eliminates life-threatening diseases and is estimated to avert 2-3 million deaths each year (WHO, 2018). Hence, it serves as a tool to save the lives of not just the individuals receiving the vaccinations, but also those around them. This is the reason why the MCH handbooks promote vaccination and include a record to remind both women and their health providers about vaccines that they should receive. 


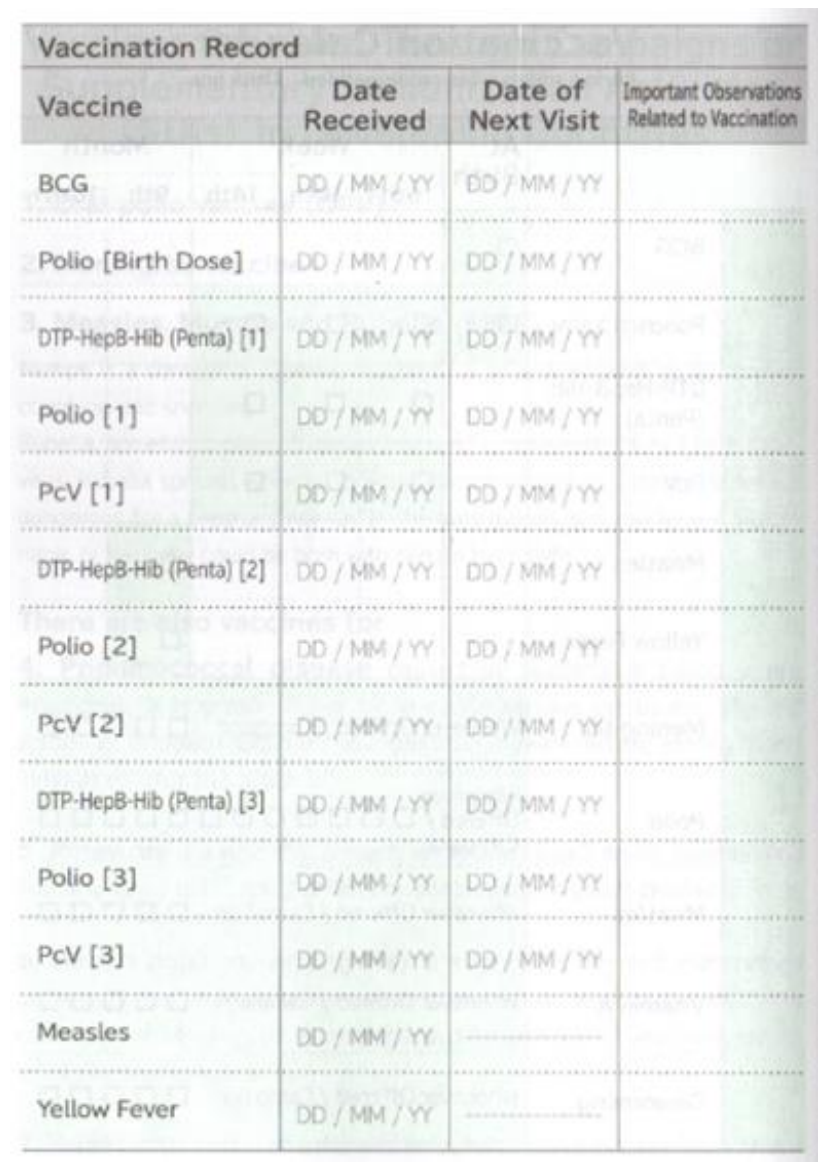

Figure 3. Page 76 of the MCH handbook in Japan display a chart that is used to make record of the vaccinations received by a child (Ministry of Health - Japan)

A study by Jeong found that pregnant women in Korea who used the $\mathrm{MCH}$ Handbook were associated with a greater awareness of DPT immunization, than their counterparts (Jeong, 2004). Knowledge was also associated with behaviour, as the number of women who received DPT immunization was significantly higher in the women who were aware of the DPT vaccine and used the MCH handbook (Jeong, 2004). Due to a lack of numbers and details on the group defined as "counterparts" the conclusions of this study are questionable (Figure 3).

Osaki et al. (2013) found that among women in Indonesia who had a child between 9 and 23 months old, $47 \%$ of the women who had both the general record given to patients and the $\mathrm{MCH}$ handbook completed 12 doses immunization, compared to the $25.1 \%$ without both records. But, it should be noted that the percentage can be attributed to either using the general record or the MCH handbook.

Osaki et al. (2018) found that women in Indonesia who used the MCH handbook, went to an ANC appointment about 6.3 times, compared to 5.6 times in the control area. Moreover, among women who went to an ANC appointment more than six times, 54.6\% of the women had a MCH handbook (Osaki et al., 2018). In addition, $43.3 \%$ of the women who had a MCH handbook sought professional childbirth care, compared to $39.1 \%$ of the control group (Osaki et al., 2018). It is interesting to note that though the numbers between the experimental group and control group are very close to each other, the use of a MCH handbook appears to increase the mother's likelihood of utilizing medical services.

\section{A Predictor of Growth - Nutrition}

Nutrition refers to the food that one intakes, in relation to the dietary needs of that individual (WHO, 2018). Poor nutrition can lead to reduced immunity, increased susceptibility to disease, impaired physical and mental development, and reduced productivity. Adequate nutrition will help a pregnant woman avoid pregnancy symptoms such as nausea and constipation (Stanford Children's Health, 2018). Additionally, the nutrients received by a developing fetus depends on the food intake of their mother, and thus the nutrition of a pregnant woman is critical to ensuring a healthy fetus (Ramakrishnan et al., 2012). For example, nutrients such as iron, zinc, iodine, and fatty acids are vital for the development of the brain and nervous system (Ramakrishnan et al., 2012). Therefore, by including culturally sensitive food recipes in the $\mathrm{MCH}$ handbooks, these books are promoting the intake of nutritious food (Figure 4).

A study by Rukminto performed interviews with women in Telogo Asri Village, Central Java, Indonesia who used the $\mathrm{MCH}$ handbook. One woman said, "There is (benefit). See, the diet is better. Now there are more vegetables. Yes...when I was pregnant, I took care of my health... to stay healthy" (Rukminto, 2006). This shows that the food choices in the handbook play a roll in shaping the diets of pregnant women. It may provide them with options that they had not considered in the past. The current MCH handbook used in Indonesia states $23+$ examples of food that a child can eat along with guidelines on what types of food is recommended for each age. 


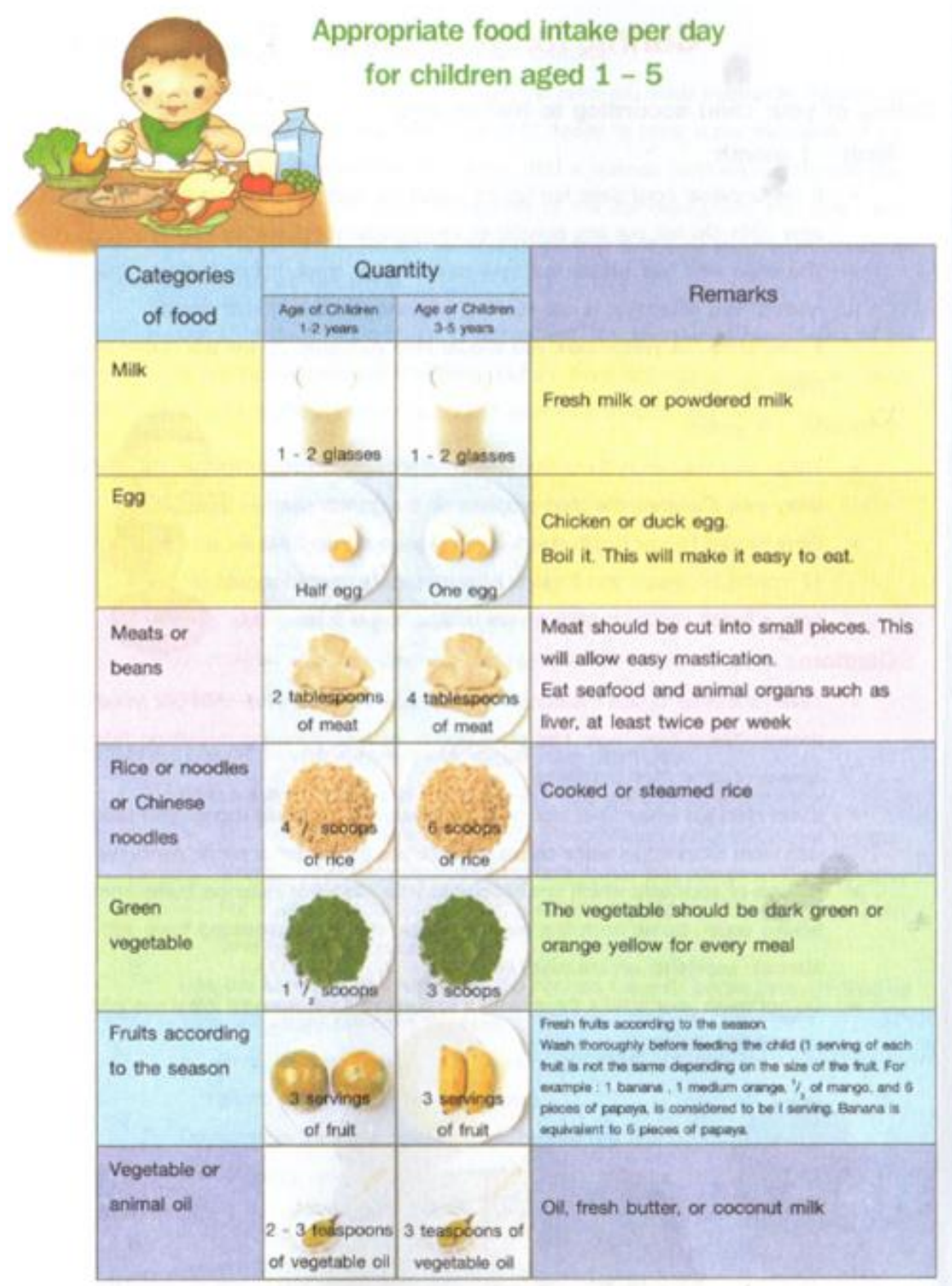

Figure 4. Page 36 of the MCH handbook in Thailand displays a chart with food choices and quantities for children between the ages of 1 and 2, and 3 and 5 (Issaranurak et al., 2006; Ministry of Health - Thailand, 2006)

Osaki, et al found that women in Indonesia who used the $\mathrm{MCH}$ handbook were more likely to feed their children complementary foods by providing fruits and/or fruits extract, foods containing protein, vitamins, and oil, and two snacks per day, along with vitamin A (Osaki et al., 2018). This may be due to the fact that handbooks in Indonesia include this information and modifies each according to each age group. Moreover, there was a decrease in the number of underweight children (5.2\% vs $14 \%)$ and children with stunted growth (26.3\% vs $40.3 \%$ ) in the group of mothers using the $\mathrm{MCH}$ handbook, in comparison to the control group (Osaki et al., 2018). This can be explained by the complementary feeding practices that mothers who used the MCH handbook may have used due to the guidelines present in the handbook. The $\mathrm{MCH}$ handbook used in Indonesia provides guidelines on what to feed and how to feed their child at 0-6 months, 6-9 months, 912 months, $1-2$ years, and $2-3$ years.

\section{Practices to Ensure a Healthy Child - Breastfeeding}

Breastfeeding has been found to prevent infectious diseases such as upper and lower respiratory tract infections, gastrointestinal illness, and otitis media (Allen and Hector, 2005). In fact, a study found that infants who were formula fed were three times more likely to have a severe respiratory tract illness, than those who were breastfed for at least four months (Bachrach et al., 2003). Moreover, breastfeeding for six months and longer has been found to reduce systolic blood pressure in older children (Allen and Hector, 2005). Studies have also shown that breastfeeding protects against morbidity/mortality from diarrhea and that the protection is higher among infants who are breastfed in the first 6 months of their life (Horta and Victoria, 2013). Breastfeeding also provides benefits for the mother, as it has been found to be protective against developing premenopausal breast cancer, with a longer duration of breastfeeding resulting in greater protection 


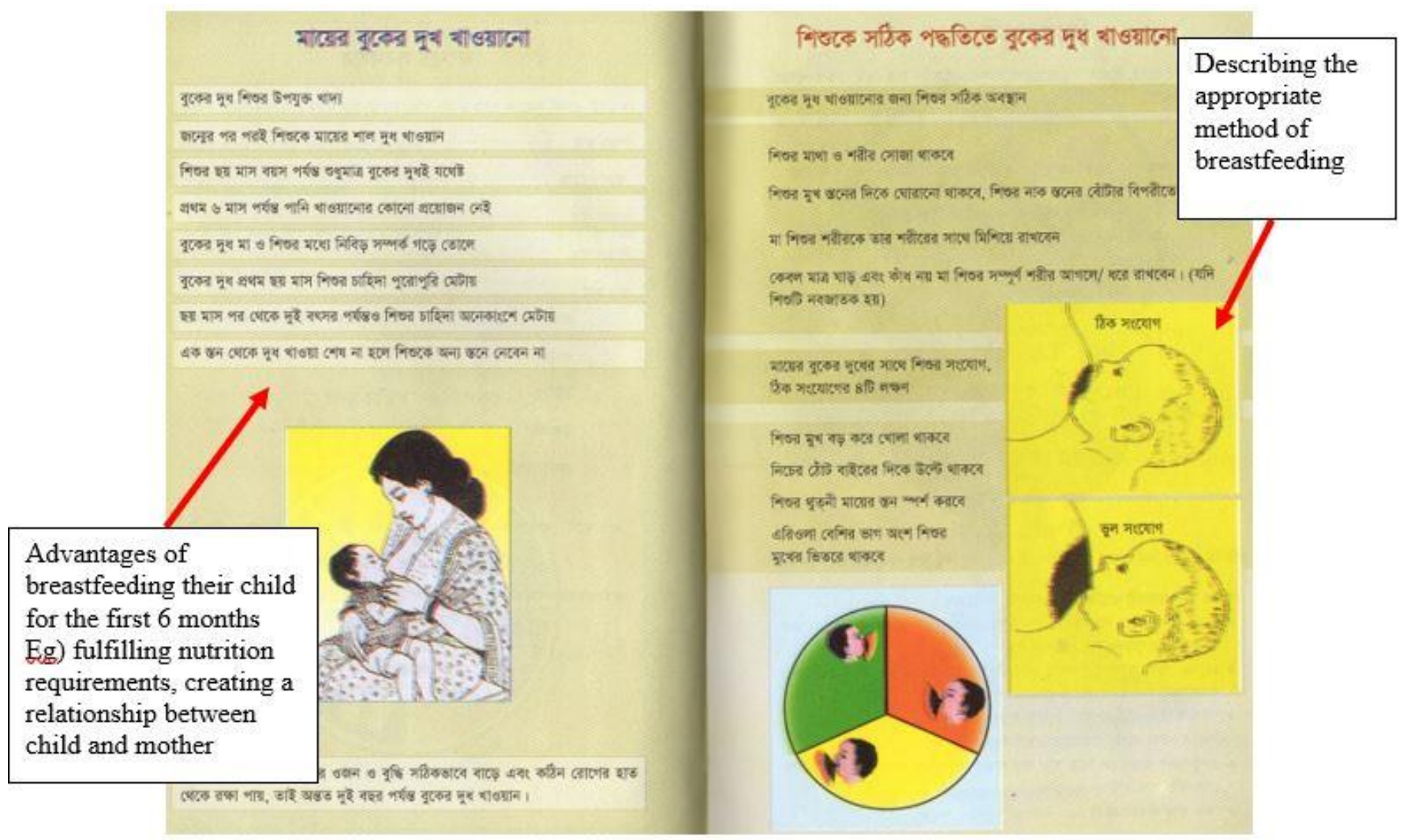

Figure 5. Pages 28 and 29 of the MCH handbook used in Bangladesh provides guidelines and information on the importance of breastfeeding (Bhuiyan, 2007)

(Horta and Victoria, 2013). Such research prompted the addition of information on breastfeeding in the $\mathrm{MCH}$ Handbooks, so that mothers learn about and use this method of feeding (Figure 5).

Aiga et al. (2015) found that using the MCH handbook increased the number of pregnant women who knew that it was essential to breastfeed their child for the first 6 months after birth $(66.1 \%$ in pre-intervention, compared to $86.7 \%$ in postintervention). This increase in knowledge seems to have also translated into a change in behaviour, as the number of women who breastfed their children until 6 months of age had increased from $18.3 \%$ in the pre-intervention to $74.9 \%$ in the post-intervention (Aiga et al., 2015). This demonstrates the powerful effect that knowledge can have in shaping behaviours and health practices. One woman in the study had stated that though she had to miss an event on maternal and child health due to the venue being held far from her home, having the handbook with its guidelines on breastfeeding made her feel a level of protection (Aiga et al., 2015). Therefore, having the $\mathrm{MCH}$ handbook and the information it provides, allows women to feel more secure about the responsibilities associated with both their health, and their child's health, when other resources are not accessible.

\section{Educating Mothers - Maternal \& Childcare Knowledge}

It comes without saying that the more you know, the better you are able to cope with the events to come. As such, the more that pregnant women know about their health during pregnancy, and changes after pregnancy, the better they are able to notice abnormalities and prepare for the changes to come. It is with this notion that the $\mathrm{MCH}$ handbooks are packed with information such as risks during pregnancies, danger signs, and guidelines on caring for their child(ren).

Yanagisawa et al. (2015) found that pregnant women in Cambodia who used the MCH Handbook, had an increase in knowledge about danger signs during pregnancy, such as swelling, persistent vomiting, and convulsions. The handbook also increased the pregnant women's awareness about danger signs during delivery, such as prolonged labour, malpresentation, and placenta accrete (Yanagisawa et al., 2015). Using the MCH handbook also increased their knowledge of anaemia, parasites, and HIV infection (Yanagisawa et al., 2015). This knowledge ensures that a pregnant woman is more aware and prepared during pregnancy and delivery.

Hagiwaraa et al. (2013) found that women in Palestine who used the MCH handbook, became more mindful of how to cope with the risks of rupture of membranes during pregnancy, especially if they had completed a lower level of education (Hagiwaraa et al., 2013). Women expressed that they felt more comfortable and confident when understanding the common symptoms and risks associated with pregnancy and childbirth (Hagiwaraa et al., 2013). This confidence allowed them to better express and relay necessary information to health provides, related to their own health, and to also better care for their child(ren) (Hagiwaraa, Ueyamab, Ramlawic \& Sawadad, 2013). Some women also mentioned that the health education messages in the MCH handbook helped them to navigate through rumors and misconceptions about pregnancy care and childcare that was miscommunicated to them by their family members and mothers-in-law (Hagiwaraa et al., 2013). 
Rukminto (2006) performed interviews with women in Telogo Asri Village, Central Java, Indonesia who used the MCH handbook. One woman had said, "Well, (the knowledge) improves. ...so I know more, if I may say so. Well, very useful, for everytime we go to the Posyandu and bring the handbook, we know how far the child's weight increases...”. This statement implies that mothers are interested in knowing the progress of their child's health upon birth. Another woman in the study said, "Yes, I can make supplements, such as porridge...then my 13-month-old baby has not begun to walk, and I can check it in the handbook. I have benefited a lot from the handbook" (Rukminto, 2016). This statement shows that women use the handbook has a guideline to make foods that serve as supplements, and also use it to learn about their child's growth and development. This knowledge ultimately provides them a sense of security and awareness of the health changes within their child(ren) and themselves.

Kawakatsu et al. (2015), in Western Kenya, found that the MCH handbook resulted in higher health knowledge and better health-seeking behavior for fever and diarrhea (Kawakatsu et al., 2015). This could be because the handbook in Kenya includes health information on how parents can care for a child who has a fever or diarrhea.

\section{Empowerment}

Despite the lack of studies which focus on whether pregnant women using the MCH handbook feel empowered, the data obtained from the present studies seem to imply that they do feel a sense of empowerment. This sense of empowerment comes along with feeling that they are more in control of both their health and the health of their child's. Hagiwaraa et al. (2013) found that pregnant women had an improved sense of control and satisfaction when they own their own maternal records (Hagiwaraa et al., 2013). Having their health records and various health information at their finger tips in a language that they can understand whether that be through words or pictorials, allows them to feel that they are in control of both their own and their child(ren)'s health. Such empowerment leads to a woman becoming more engaged and interested about health, and as the studies have shown, leads greater utilization of medical services and more positive health behaviors. Thus, the MCH handbook serves as a tool to empower patients, which ultimately leads to the bettering of their health and their child(ren)'s.

\section{Costs}

The cost of the MCH handbook varies from country to country, but it has been found that if a country uses three or more health related cards, purchasing a $\mathrm{MCH}$ handbook which is comprised of all three or more cards is more cost efficient. For example, in Bangladesh, the 5-6 cards that are used cost about $\$ 2.00$, but one $\mathrm{MCH}$ handbook costs between 30 to 50 cents (Bhuiyan, 2016). Also, a case study in Vietnam found that integrating the MCH handbook would annually save USD 3.01 million, in Vietnam (Aiga et al., 2018). More research is needed to explore the way the cost of the MCH handbook varies from country to country.

\section{DISCUSSION}

\section{Backup}

One drawback of the $\mathrm{MCH}$ handbook is that there is no backup copy of the records within the handbook. This means that if one were to lose their handbook, their records are also lost. Though the literature review showed that the number of people who lost their handbook in each group were less than $1 \%$, there still is a need to ensure a backup. One potential solution is ensuring that healthcare providers make a copy of the information recorded in the $\mathrm{MCH}$ handbook either by recording the information on their own technological device or keeping a hard copy record at their office.

\section{Healthcare Workers' Engagement}

The literature constantly showed that the effectiveness of the MCH handbook is heightened once healthcare workers also engage with it. This means that health care workers and volunteers should receive training on using and recording in the handbook. Along with providing training, healthcare workers should be monitored to ensure that they are recording information in the handbook. Moreover, healthcare workers should speak to their patients about the information in the handbook, referring to pages that they should read. Such collaboration will further allow for the $\mathrm{MCH}$ handbook to be effective among pregnant women (Nakamura, 2010).

\section{Content}

There is a continuous need to ensure that the contents of the $\mathrm{MCH}$ Handbooks (recipes, guidelines) are culturally significant to the community that is being served. There is also a continuous need to ensure that pictures and figures are added so that women who are illiterate are also able to engage with and understand the handbook. For example, in Indonesia, $30 \%-40 \%$ of the targeted mothers in the study area (and in many other areas in Indonesia) had not completed elementary school (Kusmayati and Nakamura, 2007). Their low educational level may limit their understanding of the messages in the handbook, and/or the ability to follow the advice that is given to them (Kusmayati and Nakamura, 2007). Therefore, each handbook in each country should have a variation that is solely focused on pictures and diagrams.

\section{Socioeconomic Class}

Rukminto (2006), in Indonesia, found that most of the individuals who used the MCH handbook were neither from a low socioeconomic class, or a high economic class, but rather fell somewhere in the middle. This may be because, as part of the low socioeconomic class, pregnant women were not able to purchase the food that was included in the MCH handbooks (Rukminto, 2006). Whereas those who were part of the high socioeconomic class were more educated and felt that the information in the MCH handbook was too simple (Rukminto, 2006). Moreover, women with several children were unlikely to use the MCH handbook, since they already had experience and knew about the information in the handbook (Rukminto, 2006). Thus, tended to use the MCH handbook solely to make record of appointments and vaccinations (Rukminto, 2006). There is a need for more studies that focus on the relationship 
between socioeconomic class and the usage of the $\mathrm{MCH}$ handbook, which can also relate to the livelihoods of women.

\section{CONCLUSION}

Overall, this literature review illustrated that the $\mathrm{MCH}$ handbook is an effective tool that serves to holistically enhance the health of pregnant women by empowering and educating them on the health of both themselves and their children. By serving individuals from various socioeconomic classes, this handbook ensures that 'no one is left behind', which is in fact the message behind this initiative. Providing culture specific handbooks with both words and pictorials also ensure that all pregnant women are able to engage with and relate to the content within the handbook. Moreover, by having two-way communication between healthcare providers and pregnant women and their families via the $\mathrm{MCH}$ handbook, guarantees that the health of both pregnant women and their child(ren) are taken care of at an optimal level.

Now as a step forward, the International Committee on $\mathrm{MCH}$ Handbook is currently exploring web-based versions of the $\mathrm{MCH}$ handbooks, where individuals can access them via a mobile app. This will make it more efficient for individuals who find it is easier to learn and record information via a phone. Using a phone will also create a backup for the information in the $\mathrm{MCH}$, in case the physical book is lost. Moreover, as our literature review shows, there is no 'one size fits all' handbook. For example, there is a need for handbooks that focus on recognizing mental health conditions, caring for a child with a developmental disability, and caring for a child with cerebral palsy. Such ideas are currently being explored to truly commit to the idea that no one is left behind.

In order to ensure the effectiveness of the MCH handbook and to enhance it so that it reaches more populations and addresses more needs, there is a need for greater collaboration between governments, the United Nations, donor agencies and NGOs. There is also a need for strengthening the relationships between the private and public sector. With greater collaboration comes the addressing of more needs and ensuring that every mother, regardless of her culture and socioeconomic class, is educated and empowered to positively impact both the health of her own, and her child(ren)'s.

Author contributions: All co-authors have involved in all stages of this study while preparing the final version. They all agree with the results and conclusions.

Funding: No external funding is received for this article.

Declaration of interest: The authors declare that they have no competing interests.

Ethics approval and consent to participate: Not applicable.

Availability of data and materials: All data generated or analyzed during this study are available for sharing when appropriate request is directed to corresponding author.

\section{REFERENCES}

Aiga, H., Nguyen, V. D., Nguyen, C. D., Nguyen, T. T. and Nguyen, L. T. (2015). Knowledge, attitudes and practices: assessing maternal and child health care handbook intervention in Vietnam. BMC Public Health, 16, 129. https://doi.org/10.1186/s12889-016-2788-4

Allen, J. and Hector, D. (2005). Benefits of breastfeeding. NSW Public Health Bulletin, 16(3-4), 42-46. https://doi.org/10.1071/NB05011

Allinson, M. and Chaar, B. (2016). How to build and maintain trust with patients. The Pharmaceutical Journal, 297(7895), 20201862. Available at: https://www.pharmaceuticaljournal.com/pharmacy-learning-centre/how-to-buildand-maintain-trust-with-patients/20201862.article

Bachrach, V. R., Scwarz, E. and Bachrach, L. R. (2003). Breastfeeding and the risk of hospitalization for respiratory disease in infancy: A meta-analysis. Archives of Pediatrics \& Adolescent Medicine, 157, 237-243. https://doi.org/10.1001/archpedi.157.3.237

Bhuiyan, S. U. (2007). Maternal and child health (MCH) handbook. Osaka University.

Bhuiyan, S. U. (2009). Development, field testing, and potential benefits of a maternal and child health $(\mathrm{MCH})$ handbook in Bangladesh. Journal of International Health, 24(2), 73-76.

Bhuiyan, S. U. (2016). 50 cents can save two lives. Dalla Lana School of Public Health Annual Report 2015-2016.

Bhuiyan, S. U., Nakamura, Y. and Qureshi, N. A. (2006). Study on development and assessment of maternal and child health $(\mathrm{MCH})$ handbook in Bangladesh. Journal of Public Health and Development, 4(2), 45-60.

Bureau of Health Promotion - Thailand (2008). The $M C H$ Handbook 2008. Bangkok (Thailand): Organization of Veteran Press.

Department of Maternal and Child Health - Vietnam. (2013). Maternal and child health handbook. Ministry of Health Vietnam.

Fujimoto, S., Nakamura, Y., Ikeda, M., Takeda, Y. and Higurashi, M. (2001). Utilization of Maternal and Child Health handbook in Japan. Nihon Koshu Eisei Zasshi, 48(6), 486-494. PMID:11494593

Hagiwaraa, A., Ueyamab, M., Ramlawic, A. and Sawadad, Y. (2013). Is the Maternal and Child Health (MCH) handbook effective in improving health-related behavior? Evidence from Palestine. Journal of Public Health Policy, 34(1), 31-45. https://doi.org/10.1057/jphp.2012.56

Horta, B. L. and Victoria, C. G. (2013). Short-term effects of breastfeeding - A systematic review on the benefits of breastfeeding on diarrhoea and pneumonia mortality. World Health Organization. Available at: http://apps.who.int/ iris/bitstream/10665/95585/1/9789241506120_eng.pdf

Isaraunrug, S. (2009). Maternal and child healh (mch) handbook in the world. Maternal and child health handbook in Thailand. Journal of International Health, 24(2), 61-66. 
Issaranurak, S., Woramongkol, N. and Kullurk, N. (2006). Mother and child health handbook. Ministry of Public Health - Thailand.

Jeong, I. S. (2004). The relationship between retention of the maternal child health handbook, awareness of DPT additional immunization and DPT additional immunization. Journal of Korean Academy of Community Health Nursing, 15(1), 76-83.

Kawakatsu, Y., Sugishita, Y., Oruenjo, K., Wakhule, S., Kibosia, K., Were, E. and Honda, S. (2015). Effectiveness of and factors related to possession of a mother and child health handbook: an analysis using propensity score matching. Health Education Research, 30(6), 935-946. https://doi.org/10.1093/her/cyv048

Kusmayati, A. and Nakamura, Y. (2007). Increased utilization of maternal health services by mothers using the maternal and child health handbook in Indonesia. Journal of International Health, 22(3), 143-151.

Licentto, O., Mothebesoane-Anoh, S., Gomez, P. and Munjanja, S. (2006). Chapter 2 - Antenatal Care. Opportunities for Africa's Newborns. Available at: http://www.who.int/pmnch/media/publications/aonsectio nIII_2.pdf

Ministry of Health - Indonesia (2009). Maternal and child health handbook. Japan International Cooperation Agency.

Ministry of Health - Japan (2016). For your 20-year old record: Boshi-techno - Mother and child health handbook. Parent and Child Health Handbook Promotion Association.

Mori, R., Yonemoto, N., Noma, H., Orchirbat, T., Barber, E., Soyolgerel, G., Nakamura, Y. and Lkhagvasuren, O. (2015). The maternal and child health (mch) handbook in Mongolia: a cluster-randomized, control trial. PLoS One, 10(4), e0119772. https://doi.org/10.1371/journal.pone.0119772

Nakamura, Y. (2010). Maternal and child health handbook in Japan. Japan Medical Association, 3(4), 259-265.

Nakamura, Y. and Bhuiyan, S. (2005). MCH country focused training. Osaki University.

Osaki, K., Hattori, T. and Kosen, S. (2013). The role of homebased records in the establishment of a continuum of care for mothers, newborns, and children in Indonesia. Global Health Action, 6, 1-12. https://doi.org/10.3402/ gha.v6i0.20429
Osaki, K., Hattori, T., Toda, A., Mulati, E., Hermawan, L., Pritasari, K., Bardosono, S. and Kosen, S. (2018). Maternal and child health handbook use for maternal and child care: A cluster randomized controlled study in rural Java, Indonesia. Journal of Public Health, 41(1), 170-182. https://doi.org/10.1093/pubmed/fdx175

Ramakrishnan, U., Grant, F., Goldenberg, T., Zongrone, A. and Martorella, R. (2012). Effect of women's nutrition before and during early pregnancy on maternal and infant outcomes: A systematic review. Paediatric and Perinatal Epidemiology, 26(Suppl. 285-301. https://doi.org/10.1111/j.1365-3016.2012.01281.x

Rukminto, I. (2006). The evaluation of the official development assistance programme from JICA on the maternal and child health handbook at the Telogo Asri Village, Central Java. Makara Seri Kesehatan, 10(2), 94.

Stanford Children's Health. (2018). Nutrition during pregnancy. Topics. Available at: http://www.stanfordchildrens.org/en/ topic/default?id=nutrition-during-pregnancy-85-P01227

United Nations. (2017). Progress of goal 3 in 2017. Sustainable Development Knowledge Platform. Available at: https://sustainabledevelopment.un.org/sdg3

World Health Organization (2018). Immunization. Health topics. Available at: http://www.who.int/topics/ immunization/en/

World Health Organization. (2016). Pregnant women must be able to access the right care at the right time, says WHO. News Release. Available at: http://www.who.int/media centre/news/releases/2016/antenatal-care-guidelines/en/

World Health Organization. (2018). Nutrition. Health topics. Available at: http://www.who.int/topics/nutrition/en/

Yanagisawa, S., Soyano, A., Igarashi, H., Ura, M. and Nakamura, Y. (2015). Effect of a maternal and child health handbook on maternal knowledge and behaviour: a community-based controlled trial in rural Cambodia. Health Policy and Planning, 30(9), 1184-1192. https://doi.org/10.1093/heapol/czu133 